\title{
Circumflex retroesophageal right aortic arch: rare differential of mediastinal widening
}

\author{
Niraj Nirmal Pandey, Arun Sharma, Manish Shaw, Sanjeev Kumar
}

Department of Cardiovascular Radiology and Endovascular Interventions, All India Institute of Medical Sciences, New Delhi, India

\section{Correspondence to} Dr Arun Sharma, drarungautam@gmail.com

NNP, AS, MS and SK contributed equally.

Accepted 3 July 2018

\section{DESCRIPTION}

A 48-year-old man presented to the outpatient department with complaints of inspiratory stridor and occasional dysphagia. Chest radiograph revealed bilateral symmetric widening of the superior mediastinum at the level of aortic arch with the descending aorta seen to the left of spine. No lateral displacement of tracheal air column was noted (figure 1A). The patient was referred to us for a CT angiography (CTA) with a provisional diagnosis of an aneurysm or a mediastinal mass. Review of CTA images revealed a right-sided aortic arch crossing the midline posterior to the trachea and the oesophagus in the upper mediastinum and further descending on the left side of spine (figure 1B-E). A Kommerell's diverticulum arising from the anterosuperior aspect of aorta, on the left side, gave rise to an aberrant left subclavian artery (LSCA). The circumflex arch was ectatic and measured $37 \mathrm{~mm}$ in its maximum diameter. Moderate compression on the posterior aspect of trachea by the ectatic circumflex arch was noted (figure $1 \mathrm{E}-\mathrm{F}$ ).

A circumflex retroesophageal right aortic arch is an extremely uncommon anomaly. Embryologically, a circumflex right aorta with an aberrant LSCA results from regression of the left dorsal aorta between the left common carotid artery and the LSCA, with the right dorsal aorta forming the distal portion of the arch. It has also been postulated that the third aortic arch gives rise to the proximal aortic arch while the distal arch is formed by the fourth arch, which can explain the elongated transverse arch as well as the relatively higher position of the proximal aortic arch. ${ }^{1}$ Even in the absence of a ligamentum arteriosum, the circumflex aorta itself, especially if ectatic, can cause symptomatic

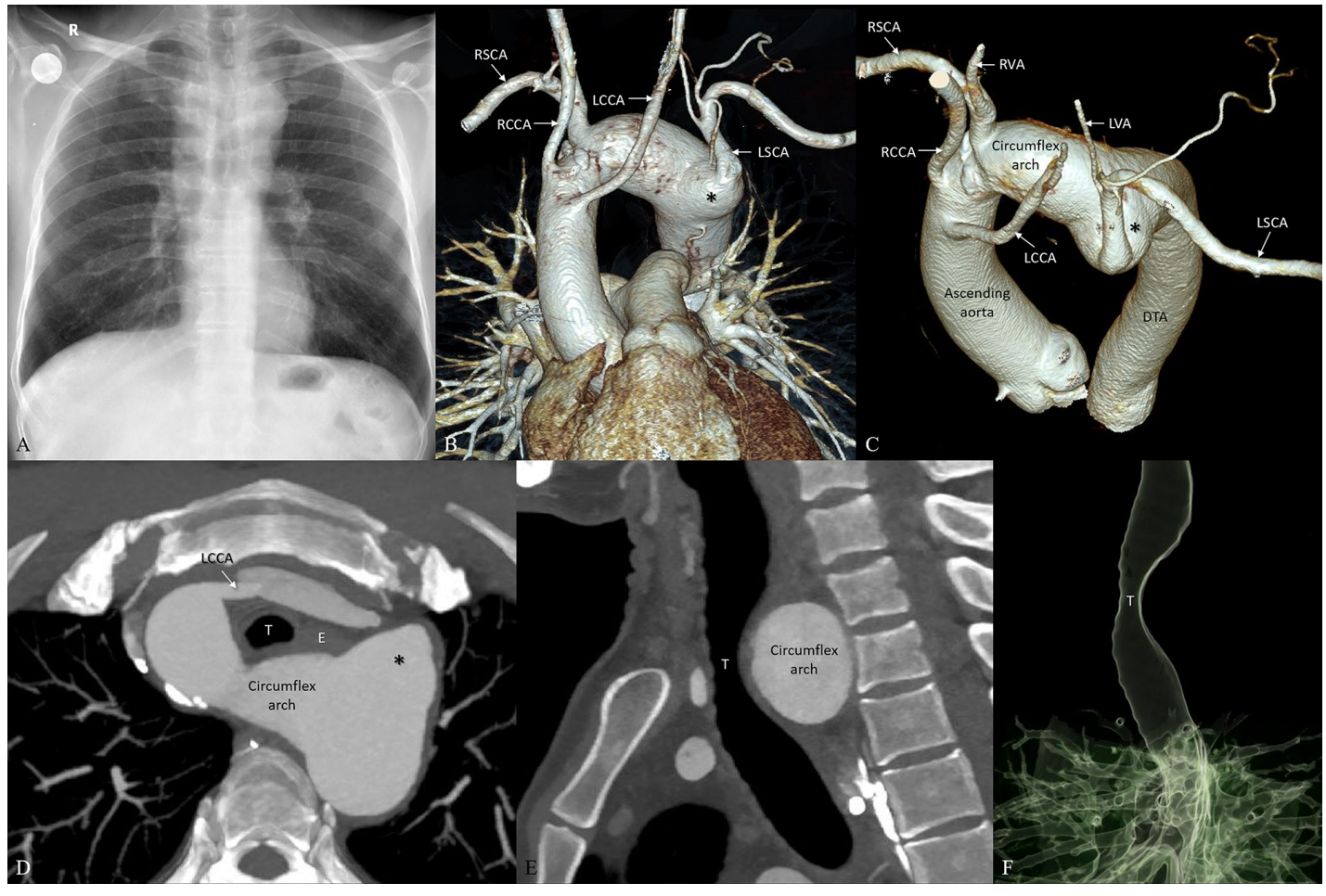

Figure 1 (A) Frontal chest radiograph reveals bilateral symmetric widening of the superior mediastinum at the level of aortic arch with the descending aorta seen to the left of spine. No lateral displacement of tracheal air column is noted. Volume-rendered images $(B, C)$ and maximum intensity projections, in the axial $(D)$ and sagittal $(E)$ view, of the CT angiography reveals a right-sided aortic arch crossing the midline posterior to the trachea $(T)$ and the oesophagus (E) in the upper mediastinum and further descending on the left side of spine. The first branch from the arch is the LCCA, followed by the RCCA, the RSCA with a Kommerell's diverticulum $\left(^{*}\right)$ arising from the anterosuperior aspect of aorta, on the left side, giving rise to the aberrant LSCA. Moderate compression on the posterior aspect of trachea (T) by the circumflex arch is noted which is also appreciated on the virtual bronchography image (F). DTA, descending thoracic aorta; LCCA, left common carotid artery; LSCA, left subclavian artery; LVA, left vertebral artery; RCCA, right common carotid artery; RSCA, right subclavian artery; RVA, right vertebral artery. 
tracheal compression, as in this case, which makes identification of this anomaly pertinent; as such, patients may require aortic uncrossing procedure, where the distal aortic arch is transected,

\section{Learning points}

Circumflex retroesophageal right aortic arch can mimic an aneurysm or a superior mediastinal mass on a chest radiograph.

- Identification of this anomaly is important as, even in the absence of a ligamentum arteriosum, the circumflex aorta itself, especially if ectatic, can cause symptomatic tracheal compression and such patients may require aortic uncrossing procedure. the retroesophageal segment mobilised and brought anterior to trachea followed by its anastomosis with the ascending aorta. ${ }^{2}$

Contributors All authors have participated sufficiently in the conception of the idea, development of the intellectual content, design, writing and final approval of the manuscript.

Funding The authors have not declared a specific grant for this research from any funding agency in the public, commercial or not-for-profit sectors.

Competing interests None declared.

Patient consent Obtained.

Provenance and peer review Not commissioned; externally peer reviewed.

\section{REFERENCES}

1 Hanneman K, Newman B, Chan F. Congenital variants and anomalies of the aortic arch. Radiographics 2017:37:32-51.

2 Russell HM, Rastatter JC, Backer CL. The aortic uncrossing procedure for circumflex aorta. Operative Techniques in Thoracic and Cardiovascular Surgery 2013;18:15-31.

Copyright 2018 BMJ Publishing Group. All rights reserved. For permission to reuse any of this content visit http://group.bmj.com/group/rights-licensing/permissions.

BMJ Case Report Fellows may re-use this article for personal use and teaching without any further permission.

Become a Fellow of BMJ Case Reports today and you can:

- Submit as many cases as you like

- Enjoy fast sympathetic peer review and rapid publication of accepted articles

- Access all the published articles

- Re-use any of the published material for personal use and teaching without further permission

For information on Institutional Fellowships contact consortiasales@bmjgroup.com

Visit casereports.bmj.com for more articles like this and to become a Fellow 